\title{
Cartas d'alma: um intercâmbio cultural e afetivo
}

[ Letters from the soul: a cultural and affective exchange

\section{Rodrigo Jorge Ribeiro Neves ${ }^{\mathrm{T}}$}

PONCIONI, Claudia; CAMILOTTI, Virginia (Org.). Muito d'alma: cartas de Paulo Barreto (João do Rio) a João de Barros - I909-I92I. Rio de Janeiro: Academia Brasileira de Letras/ Garamond, 2015.

Escrevo a correr - só para matar saudades. (Paulo Barreto a João de Barros, em carta de I9I4)

Uma vida não se conta. Ela se recolhe, se pulveriza, busca se reconstruir ou se

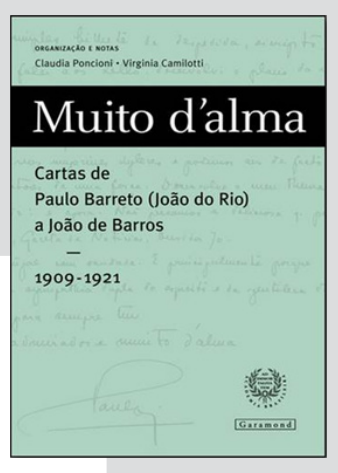
dissolve em algum modo como flui o tempo, como flui um rio até o mar. Uma vida que se pretende contar já surge como fragmento antes mesmo da intenção, pois o passado é também uma forma extraviada de vida, onde recolhemos os vestígios de uma história para dar-lhes outro sentido, inteligível, fulgurante e real. Em uma edição de cartas, em que mais de uma vida se entrecruza, essa fragmentação se amplia e oferece um olhar prismático tanto sobre os missivistas quanto sobre o contexto em que estão inseridos. E o livro Muito d'alma: cartas de Paulo Barreto (João do Rio) a João de Barros - I909-I92I, organizado por Cláudia Poncioni e Virginia Camilotti, surge como exemplar nesse sentido.

NEVES, Rodrigo Jorge Ribeiro. Cartas d'alma: um intercâmbio cultural e afetivo. Revista do Instituto de Estudos Brasileiros, Brasil, n. 68, p. 248-253, dez. 2017.

DOI: http://dx.doi.org/Io.II606/issn.23I6-90IX.voi68p248-253

I Universidade de São Paulo (USP, São Paulo, SP, Brasil). 
Conduzida com exaustivo levantamento documental e esmerado rigor crítico-analítico, a publicação faz parte das atividades científicas do projeto "Artífices da correspondência: procedimentos teóricos, metodológicos e críticos na edição de cartas", realizado em parceira entre o Instituto de Estudos Brasileiros da Universidade de São Paulo (IEB/USP) e o Centre de Recherches sur les Pays Lusophones (Crepal) da Université Sorbonne Nouvelle, Paris 3.

A edição reúne 66 cartas enviadas pelo escritor e jornalista brasileiro Paulo Barreto (I88I-I92I), mais conhecido como João do Rio, ao escritor e jornalista português João de Barros (I88I-I960), entre I909 e I92I. Desse conjunto, 63 manuscritos autógrafos são mantidos no acervo de João de Barros na Biblioteca Nacional de Portugal e três pelos herdeiros do escritor português. A reciprocidade, infelizmente, não pôde ser estabelecida devido à dispersão dos documentos de Paulo Barreto, apesar dos cuidados de sua mãe na doação do acervo do filho para o Real Gabinete Português de Leitura do Rio de Janeiro. Contudo, as organizadoras do livro souberam extrair de uma das vozes as ressonâncias e justaposições da outra, revelando-se, assim, o espaço semântico-acústico em que se (re)encenam os sujeitos da escrita epistolográfica. As relações de cada um dos missivistas com as referências dadas no diálogo também agregam ainda mais vozes na tessitura de suas vidas em correspondência. Outra dificuldade relatada pelas estudiosas foi a quase total ausência de datação nas missivas coligidas - apenas nove apresentam o registro do calendário. Por meio de percuciente cotejo de índices temporais, como obras, pessoas e colaborações referenciadas, foi possível definir uma adequada ordenação cronológica e, com isso, reconstituir os passos do autor de A alma encantadora das ruas na direção do amigo que acenava da calçada quase oposta, do outro lado do Atlântico.

E para lá partiu Paulo Barreto, pela primeira vez, em I908, retornando outras três vezes. Diferentemente da maioria dos intelectuais e escritores da época, entrou no continente europeu por Lisboa, travando relações com diversos representantes das letras lusitanas de então, entre romancistas, dramaturgos e diretores de periódicos. Esse contato foi fundamental não apenas para a maturação intelectual e estética do escritor João do Rio, mas, principalmente, para o estreitamento das relações entre Brasil e Portugal por meio do intercâmbio cultural e afetivo de suas respectivas 
produções, pois o turismo empreendido pelo escritor carioca levou-o também aos braços de uma grande e sincera amizade.

$\mathrm{Na}$ apresentação ao livro, intitulada "Nas esferas do poder: letras, políticas e finanças nas cartas de Paulo Barreto ao seu amigo João de Barros", as organizadoras afirmam que as "cartas se situam [...] numa ambiência de crescente denegação simbólica de Portugal no Brasil, ou, no melhor dos cenários, em meio à disputa pelo lugar de Portugal nas trocas interculturais do Brasil” (p. 27). Em um momento em que o Rio de Janeiro, então capital da República, era palco de intenso antilusitanismo, tanto das camadas mais populares quanto da elite burguesa, os esforços de Paulo Barreto e de João de Barros se mostram audaciosos e impregnados de um olhar sensível para a importância do restabelecimento de laços entre os dois povos: "Em arte - o q. Portugal e o Brasil precisam é: intenção, proporção e ânimo" (p. 26, carta de I9I2). Para isso, não se eximem de buscar os meios que permitam celebrar condições para essa reaproximação, desde os círculos literários e intelectuais até as instâncias governamentais luso-brasileiras.

Os dois escritores já eram consagrados em seus respectivos círculos intelectuais e artísticos quando começaram a se corresponder, em I909. A primeira carta de Paulo Barreto é enviada enquanto ele estava em solo europeu, em Paris, e nela já se esboçam a dedicação ao intercâmbio cultural e a afetividade envolvida na aproximação dos dois escritores. $O$ vigor dessa relação se revela no uso extensivo de advérbios de intensidade ("Muito bom dia e muita saudade daqueles violentos almoços nossos") e do pronome possessivo ("Teu d'alma”) na despedida logo nesse primeiro contato, bem como a abundância verbal que busca traduzir o grau de intimidade e cumplicidade, além de dirimir possíveis equívocos que uma comunicação de intervalos tão longos possa suscitar. Desde então, a troca de informações, os pedidos de livros, artigos e contribuições em ações institucionais que pudessem facilitar a aproximação dos dois países foram se tornando cada mais frequentes.

Como é próprio da escrita epistolar, os temas são variados e se entrecruzam na partilha dos lugares ocupados pelos sujeitos circunscritos no diálogo, ainda que tenhamos acesso a apenas um dos lados, estando o outro sub-repticiamente inserido nas camadas do texto que, neles (e por eles), se inscreve. Contudo, dois assuntos atravessam insistentes as missivas reunidas e, de algum modo, dão o tom do modo como se constrói a relação entre os dois: os periódicos e o teatro. No primeiro caso, além das eventuais colaborações em jornais diversos, é preciso destacar a empresa dos missivistas no intercâmbio intelectual e artístico dos dois países, que talvez seja uma das publicações mais relevantes dessa natureza na vida cultural lusófona do século XX: a revista Atlântida (I9I5-I920).

Cada um dos correspondentes ficaria a cargo da direção da revista em seus respectivos países, que contribuíram institucionalmente para a sua realização. No Brasil, o Ministério das Relações Exteriores e, em Portugal, os ministérios dos Estrangeiros e do Fomento (designado do Comércio em 19I7) patrocinaram a iniciativa dos dois jornalistas, que, desde a concepção da primeira edição, lançada em I5 de novembro de I9I5, se mostrava ambiciosa: "Tenho muita coisa prometida./ A colaboração será de artistas e políticos e escritores de maior relevo no Brasil [...]. 
Acho q. devemos ter um prefácio assinado A Direção em q. juntaremos ideias nossas./ O I ${ }^{\circ}$ número deve ser estupendo para pegar" (p. II3, carta de I9I5).

Outro importante periódico que integra o convênio luso-brasileiro é o jornal A Pátria, fundado em I4 de novembro de I920, que se definia, no subtítulo, como "uma campanha pela fraternidade latina e aproximação de Brasil e Portugal”. Embora tenha sido extinto em I940, o jornal havia se desvirtuado completamente da linha editorial de seu fundador desde o ano de seu falecimento, em I92I. Como destacam Claudia Poncioni e Virginia Camilotti, esse periódico marca o fim da relação de Paulo Barreto e João de Barros, em um momento de "exaustão e das intensas pressões políticas e financeiras contra o jornal” (p. 28), levando ao isolamento do escritor carioca. Em uma de suas últimas cartas, em papel timbrado do jornal recém-criado, Paulo Barreto evidencia o sucesso da publicação, mas sem deixar de apontar para "a ruína e a agonia" que as circunstâncias financeiras o lançavam: "A Pátria é o maior êxito jornalístico do Brasil em todos os tempos [...]. Apesar do êxito retumbante, é o êxito catastrófico, porque os viscondes da colônia, o Banco da Financial, e outros não só não me dão, como nem letras me aceitam" (p. 229, carta de I92I).

Nas cartas, também assume importante papel de destaque o teatro. E é interessante pensar na amplitude assumida pela dimensão cênico-dramatúrgica das cartas de Paulo Barreto. Elas compreendem não apenas o tema da atividade teatral em si e de toda indústria cultural por ela mobilizada, mas também a própria carta como instância cênica, ensejada pela natureza do gênero epistolar, na medida em que faz uso de estratégias que a revestem de portadora de certa verdade. Para Nora Esperanza Bouvet, "a estratégia mais importante para obter este efeito é a 'encenação' discursiva da situação de comunicação real, metáfora teatral que remete tanto à elaboração de personagens imaginários (persona, no sentido latino de máscara, dramatis personae)

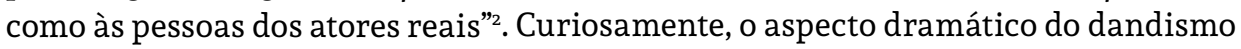
do escritor carioca, à maneira de Oscar Wilde, sai de cena a partir do momento em que ele, com exceção das duas primeiras missivas, assina como Paulo Barreto, e não João do Rio, o nome do dândi que estampa a maioria de seus artigos na imprensa, as capas de seus livros, o papel timbrado de algumas cartas e os cartazes de suas peças de teatro. Contudo, no trânsito entre os nomes, não saem de cena as estratégias da escrita epistolar, mas se reconfiguram em novos procedimentos de atuação no espaço da intimidade que se abre em uma correspondência: "Desabafo contigo, e vou escrever em estilo comercial aos bons Lello" (p. 50, carta de I9II).

Como bem lembram as organizadoras, o teatro era "uma das principais atividades culturais compartilhadas por portugueses e brasileiros no início do século XX” (p. 23). A exportação e a importação de espetáculos teatrais entre os dois países, portanto, eram fundamentais para estreitar ainda mais suas relações. Entretanto, a cooperação mútua nem sempre era exitosa. Em algumas de suas cartas, Paulo Barreto revela os entraves que enfrentava para que suas peças fossem encenadas nos palcos lisboetas, como o caso de

2 BOUVET, Nora Esperanza. La escritura epistolar. Buenos Aires, Eudeba, 2006, p. 77 (tradução livre minha). No original: “La estratégia más importante para lograr este efecto es la 'puesta en escena' discursiva de la situación de comunicación real, metáfora teatral que remite tanto a la elaboración de personajes imaginários (persona en el sentido latino de máscara, dramatis personae) como a las personas de los actores reales". 
Vitoriano Braga, importante dramaturgo e encenador português, que havia dado "evasivas habituais", como se dispensasse a peça antes de tê-la lido: "ou Braga era pouco entendido em coisas de teatro (o q. eu sei q. não é) ou não querendo:/ $\mathrm{I}^{\circ}$. uma peça teatral $/ 2^{\circ}$. uma peça de brasileiro/ $3^{\circ}$. uma peça feita para os atores de sua companhia/ Isto é, três elementos de êxito no momento - só pode ser considerado de má vontade" (p. 7I, carta de I9I2). Em outra situação, expõe sua mágoa com a classe teatral portuguesa, a quem acusava de ingratidão, mesmo depois de ter feito uso da crítica, espaço de divulgação e legitimação, em benefício de seus integrantes: "porque não há nenhum desses empresários, desses atores, desses autores de meio quarto d'água a q. eu não tenha auxiliado com prestígio e louvores injustos em Io anos de crítica num jornal como $A$ Gazeta, de q. não ignoras a influência artística, literária e social” (p. 87, carta de I9I3).

Ainda sobre a edição das cartas, é preciso destacar o exímio processo de anotação empreendido pelas organizadoras, resgatando os fios da trama do tempo em que uma galeria de personagens e paisagens atravessaram, marcadas, então, em tintas e papéis. Assim, as notas não se limitam à descrição de seu referente, mas, seguindo os pressupostos de Colette Becker, "auxiliam na leitura de textos que, em função da natureza da carta, traçam um diálogo que se mantém parcialmente desconhecido, restituem uma vivência alusiva e sincopada"3. Em princípio, a intenção era publicar uma edição apenas anotada das cartas. Contudo, em virtude da publicação anterior das cartas de Paulo Barreto, Claudia Poncioni e Virginia Camilotti não apenas procederam à reunião e anotação do texto a partir dos manuscritos do escritor, mas também produziram uma edição crítica, já que era preciso remeter à edição preexistente do texto.

O livro Cartas de João do Rio: a João de Barros e Carlos Malheiro Dias 4 , lançado em 2012 pela Fundação Nacional de Artes - Funarte, foi organizado e anotado por Cristiane d'Avila e teve seu texto estabelecido por Celimar de Oliveira, em uma edição atraente, cuidadosa em seu projeto gráfico e com uma informativa introdução feita pela organizadora. Contudo, alguns critérios críticos e editoriais adotados por D’Avila e Oliveira não contribuíram para a eficiente restituição da comunicabilidade epistolar, tarefa difícil, mas essencial em qualquer trabalho de edição de cartas.

Uma das escolhas problemáticas da edição de 2012 já aparece estampada na capa: o título. Como mencionado anteriormente, a assinatura, em quase todas as cartas, do nome verdadeiro do escritor carioca, e não do pseudônimo que o consagrou, é reveladora das condições em que foi construída a relação entre os correspondentes. Por essa razão, ao ignorar o deslocamento de um importante índice de espacialidade discursiva, a edição de D’Avila não recupera a constituição das bases em que se inscreve essa relação.

O estabelecimento do texto também compromete a restituição da comunicabilidade epistolar ao aferi-lo a partir de critérios pouco consistentes, como, por exemplo, quando decide pela não conservação de formas como "q." (que) e "v." (você), mantidas em Muito d'alma, que restabelece o "estilo telegráfico" do cronista do Cinematógrafo e a premência do intercâmbio e da amizade. De mais a mais, a

3 BECKER, Colette. O discurso da escolta: as notas e seus problemas (o exemplo da correspondência de Zola). Tradução Ligia Ferreira. Patrimônio e Memória, São Paulo, Unesp, v. 9, n. I, jan./jun. 20I3, p. I48.

4 D’AVILA, Cristiane (Org.). Cartas de João do Rio - a João de Barros e Carlos Malheiro Dias. Prefácio: Zuenir Ventura. Rio de Janeiro: Funarte, 2012. 
edição organizada por Poncioni e Camilotti retifica alguns equívocos na transcrição dos manuscritos feita pela anterior, além de elucidar trechos antes marcados como ininteligíveis. Deve-se destacar ainda a anotação mais meticulosa e acertada de Muito d'alma, contribuindo, inclusive, para uma cronologia ainda melhor encadeada das cartas, por meio da identificação de nomes e eventos decisivos para uma precisa localização temporal de cada uma delas.

É evidente que a ausência, em Cartas de João do Rio, das três missivas mantidas pelos herdeiros de João de Barros, depois obtidas e integradas por Poncioni e Camilotti em seu trabalho, não constitui um grave problema metodológico, visto que a pesquisa em epistolografia demanda perseverante e reiterada escavação arquivística, levando-nos ao resgate constante do texto, que nunca é definitivo.

Os desvios, as lacunas e as fissuras com os quais esbarramos no percurso investigativo, de algum modo, refletem os conflitos com os quais lidamos cotidianamente, na urgência da saudade e dos dias emulada pelo correr desconcertado da pena, uma "pena vadia", tal como a do conselheiro Aires de Machado de Assis5. No final, fica o lamento pelas restrições da vida ordinária, mas também a alegria de ter alguém com quem queremos compartilhar tudo o que resta: "Que pena não termos dinheiro para vivermos juntos a passear! Realizaríamos os dois uma estupenda obra de Beleza e de Fé” (p. 232, carta de abril de I92I).

SOBRE O AUTOR

RODRIGO JORGE RIBEIRO NEVES é pesquisador de pós-doutorado do Instituto de Estudos Brasileiros da Universidade de São Paulo (IEB/USP) e bolsista Fapesp, com o projeto "Edição de texto fidedigno e anotada da correspondência de Mário de Andrade e Carlos Lacerda”.

E-mail: rodrigorirn@gmail.com

\section{REFERÊNCIAS BIBLIOGRÁFICAS}

ASSIS, Machado de. Memorial de Aires. 6. ed. São Paulo: Ática, 2000.

BECKER, Colette. O discurso da escolta: as notas e seus problemas (o exemplo da correspondência de Zola).

Tradução Ligia Ferreira. Patrimônio e Memória, São Paulo, Unesp, v. 9, n. I, jan./jun. 20I3, p. I44-I56. BOUVET, Nora Esperanza. La escritura epistolar. Buenos Aires, Eudeba, 2006. (Enciclopedia Semiologica). D’AVILA, Cristiane (Org.). Cartas de João do Rio - a João de Barros e Carlos Malheiro Dias. Prefácio: Zuenir

Ventura. Rio de Janeiro: Funarte, 2012.

5 ASSIS, Machado de. Memorial de Aires. 6. ed. São Paulo: Ática, 2000, p. 35. 